\title{
Failure properties of 352 explanted silicone-gel breast implants
}

\author{
Walter Peters PhD MD FRCSC, Dennis Smith PhD DSc FRCS, Stanley Lugowski \\ MSc \\ Division of Plastic Surgery and the Centre for Biomaterials, Wellesley Hospital and the \\ University of Toronto, Toronto, Ontario
}

W Peters, D Smith, S Lugowski. Failure properties of 352 explanted silicone-gel breast implants. Can J Plast Surg 1996;4(1):55-58. There have been three generations of silicone-gel breast implants. First generation implants (thick wall - thick gel with Dacron patches) were made from 1963 to 1972. Second generation implants (thin wallthin gel) were made from 1972 until the mid 1980s. The introduction of third generation implants (stronger wall, low-bleed) was geographically dependent. In Canada, Dow Corning Silastic II implants were introduced in 1986, and Surgitek SCL implants were introduced in 1988. In the present study, a total of 352 silicone-gel breast implants were removed from 239 patients between 1981 and 1995. Their failure properties were dependent upon their generation (year of manufacture) and, for second generation implants, their duration in situ. Of the 352 implants, 20 were first generation, and all were fully intact. Twenty-eight were third generation implants, and 27 were fully intact. Failure properties of the 302 second generation implants were dependent upon their duration of implantation. A survival curve indicated that these implants began to fail (by leaking or rupturing) after four years in situ. By six years, 40\% had failed. After 12 years, 95\% had failed. Of the 171 second generation implants removed between 1991 and 1995, 77\% had failed. The failure properties were similar for the three main manufacturers: Dow Corning, Heyer-Schulte and Surgitek. The failure rate for second generation implants is much higher than was previously believed. This is particularly significant in view of the current difficulty in diagnosing implant failure.

Key Words: Breast implant, Rupture, Silicone-gel

Caractéristiques de 352 implants mammaires au gel de silicone retirés pour défectuosité

RÉSUMÉ: Nous avons connu trois générations de prothèses mammaires au gel de silicone. La première génération de prothèses (paroi épaisse, gel épais avec pièce Dacron) a été fabriquée de 1963 à 1972. Les prothèses de deuxième génération (paroi mince, gel mince) ont été fabriquées de 1972 jusqu'au milieu des années 1980. La 
producton de la troisième généneration de prothèses (paroi plus résistante, hémorragie minime) a varié selon certains facteurs géographiques. Au Canada, les prothèses DowCorning Silastic II ont fait leur entreé en 1986 et les prothèses Surgitek SCL, en 1988. Dans le cadre de la présente etude, 352 prothèses mammaires au gel de silicone ont été retirées de 239 patientes entre 1981 et 1995 . Les propriétés liées à leur échec dépendaient de la génération dont elles faisaient partie et, dans le cas d'implants de deuxième génération, de la durée de leur presence in situ. Sur les 352 prothèses, 20 étaient de première génération et toutes étaient intactes. Vingt-huit étaient de troisième génération et 27 étaient entièrement intactes. Les propriétés des 302 prothèses de deuxième génération défectueuses dépendaient de la durée de leur implantation. Selon une courbe de survie, ces prothèses on commencé à être défectueuses (à fuir ou à se romper) après quatre ans in situ. Au bout de six ans, $40 \%$ étaient défectueuses; après huit ans, $95 \%$ étaient défectueuses. De ces 171 prothèses de deuxième génération, retirées entre 1991 et 1995, 77 \% étaient défectueuses. Les défectuosités étaient semblables pour les trois grands fabricants : Dow Corning, Heyer-Schulte et Surgitek. Le taux d'échec des prothèses de deuxième génération est beaucoup plus éléve qu'on l'avait d'abord cru. Cela revêt une importance significative, compte tenu de la difficulté actuelle à diagnostiquer les défectuosités des prothèses.

An understanding of the evolution of silicone-gel breast implants is important in order to analyze their failure properties. These implants were initially introduced in 1963 by Dow Corning as a 'new natural feel prosthesis'. From 1963 until 1972, Dow Corning had a nearly exclusive monopoly on their manufacture. These 'first generation' implants were composed of a thick (firm) gel and a thick elastomeric wall. They had woven Dacron patches on their posterior surface to anchor them to the chest wall in an attempt to prevent ptosis. These implants have proven to be much stronger than those developed subsequently (1). Surgeons soon learned that many women who received these implants developed very firm (and often painful) breasts. This was due to capsular contracture, a process that was not well understood. Manufacturers surmised that this firmness was due to the firmness of the implants. They therefore decided to make implants that felt softer, with the naive notion that these softer (second generation) implants would result in softer breasts.

In 1970, Don McGhan -- who had been the chief engineer at Dow Corning from 1963 to 1970 -- joined Heyer-Schulte and subsequently developed the first soft ('Cohesive') gel implant. Heyer-Schulte released this implant in 1972, featuring "a silicone-gel with a high degree of softness previously unknown to the medical profession".

Medical Engineering Corporation (which subsequently became Surgitek), introduced a similar product in the United States in 1972, but it was not released in Canada until 1979. Dow Corning introduced a comparable product (the 'Responsive Gel') in the United States in 1975, and in Canada in 1978. All second generation implants had a 'softer gel' and a thinner wall than first generation implants.

Some manufacturers continued to offer fixation patches as options on second generation implants, but they were usually composed of (solid) silicone rather than 
Dacron, or Dacron embedded in silicone sheeting. These patches resulted in less fixation than the original Dacron patches. As more of these 'softer' implants were inserted, their failure properties began to become evident. Occasionally, implants would break during insertion. Others were found to be ruptured at open capsulotomy. Manufacturers responded to these findings in their product inserts, stating that "currently available mammary protheses are not perfect -- the elastomer has a low tear strength and is thin to achieve softness". Manufacturers initially endorsed the autoclaving of silicone-gel implants. Subsequently, when the walls of these implants were noted to tear easily (particularly if they were still hot), companies added a disclaimer against autoclaving.

Surgeons soon noticed that many patients who had received second generation implants also developed firm breasts, in spite of the 'soft' nature of the implants. In 1975, the concept of closed capsulotomy was introduced, whereby a firm breast could be vigorously squeeezed by the surgeon, to 'break down' the scar tissue around the implant and thereby reduce the firmness (2). Initially, manufacturers endorsed this method of treatment in their product inserts. However, by 1976 it was noted that some patients who had undergone this manipulation had developed implant rupture. Implant companies then changed their product inserts, to provide a disclaimer against closed capsulotomy, and to state that if an implant is ruptured, it should be replaced. In 1978, the pressures generated during closed capsulotomy were shown to be in the order of 15 pounds per square inch (2). This strengthened the concept that implants could rupture during closed capsulotomy.

Throughout the 1970s, saline inflatable implants were also marketed by many implant manufacturers. However, the high rate of spontaneous deflation of these implants was notorious. Most surgeons therefore usually preferred to use silicone-gel implants. The American Society of Plastic and Reconstructive Surgery has estimated that from 1963 to 1992, over 95\% of all breast implants inserted were made of silicone-gel (3) rather than saline.

As the failure properties of the soft 'second generation' implants became more apparent, further studies demonstrated measureable levels of silicone in the capsules surronding implants (3). It was thought that this 'free silicone' could contribute to capsular contracture. Since 1978, it has been recognized that a small amount of silicone can be expected to 'bleed' from all clinically intact gel implants (3). This phenomenon has been shown to increase under load, and to involve primarily low molecular weight components $(6,000$ to 10,000$)$ (4). More recently, these silicone bleed levels have been shown to be much higher than was anticipated. In fact, the capsule silicon levels (derived from silicone by extraction of capsular tissue with organic solvents) with intact siliconegel implants have recently been shown to be comparable to the capsule silicon levels with ruptured implants (5).

Manufacturers addressed the problems of rupture and bleed by developing the 'third generation' implant, which had a stronger shell (High Peformance [HP] elastomer), and an inner surface which was coated with a 'barrier layer' to reduce the diffusion of silicone. In 1974, the American Hospital Supply Company acquired Heyer-Schulte and Don McGhan and his team formed a new company -- McGhan Medical. The company released the first 'third generation' implant -- the Intrashiel -- in 1979. It had a diphenyl barrier layer of proprietary composition, between an inner and outer layer of HP elastomer. Other companies followed with similar types of implants, The 'new' Dow Corning (Silastic II) implant had a fluorosilicone layer to restrict silicone bleed (about 
$50 \%$ of the methyl groups on the polysiloxane chains were replaced with trifluoropropyl groups). The corresponding Surgitek implant (Strong Cohesive Low-Bleed [SCL]) also had a diphenyl barrier layer. Other companies introduced other types of barrier layers. The introduction of third generation implants was geographically dependent. The Silastic II implant was introduced by Dow Corning in the United States in 1981 and in Canada in 1984. The Surgitek SCL implant was introduced in the United States in 1986 and in Canada in 1988. Any study of implant failure must therefore take into account the geographic location of the study.

In addition to the 'bleed' phenomenon, silicone-gel implants can fail by leaking or rupturing. Leaking implants have visibly sticky silicone-gel on their surface, and in the implant pocket. The silicone will 'string out' over a variable length (6). These implants usually demonstrate a small hole (often only a pinhole) when pressure is applied to them (5). Ruptured implants demonstrate frank tears in the implant shell.

\section{MATERIALS AND METHODS}

The present retrospective study was designed to analyze the failure properties of 352 silicone-gel breast implants, which were explanted (by WP) from 1981 to 1995. Over half of the implants had originally been inserted by other surgeons. Patients from two time intervals were evaluated: 1981 through 1991; and 1992 through 1995.

These two populations were different. In the first group (1981 through 1991), 169 silicone-gel implants were removed from 125 patients. Most of these patients (96\%) sought treatment because of capsular contracture. All of these patients except one had their implants replaced.

In the second group (1992 through 1995), 217 implants were removed from 115 patients. This group was affected by the increased negative publicity about silicone-gel breast implants. Many were concerned about the ultimate safety of their implants. Over half of these patients elected to forego the insertion of further implants. The remainder had saline implants inserted.

\section{RESULTS}

Implant integrity: Of the 169 second generation implants which were removed from 1981 through 1991, the median implantation time was only two years. The failure rate was $13.7 \%$. This group provided data for the early failure rates of second generation implants (one to four years). Of the 217 implants removed from 1992 through 1995, the median implantation time was five years. The integrity of these implants was dependent upon the generation of the gel implant and, for second generation implants, the duration of implantation. Of the 217 implants, 18 were from the first generation (1961 to 1972) (Table 1). These were all fully intact. Twenty-seven of 28 of the implants from the third generation were also fully intact. Of the 171 implants from the second generation, only $23 \%$ were intact -- $77 \%$ had leaked or ruptured. 
TABLE 1: Implant status versus implant generation for 217 silicone-gel breast implants removed between 1991 and 1995. Failed implants had leaked or ruptured.

\begin{tabular}{||l|l|l|}
\hline Generation & $\mathbf{N}$ & Failed (\%) \\
\hline $1.1963-1972$ & 18 & $0(0)$ \\
\hline 2. 1973-1987 & 171 & $132(77)$ \\
\hline 3. 1988-1992 & 28 & $1(4)$ \\
\hline
\end{tabular}

Failure properties of second generation implants: The failure properties of 312 second generation implants were evaluated as a function of their duration in situ. The failure of these second generation implants was dependent upon the duration of implantation (Figure 1). Second generation implants began to fail (by leaking or rupturing) after about four years. Failure then increased with time in situ. When leaking and ruptured implants were combined (Figure 2), about $40 \%$ of the implants had failed by six years. After 12 years, about $95 \%$ of these implants had failed. There were no significant differences between the rupture rates of the three main manufacturers: Dow Corning, Heyer-Schulte and Surgitek.

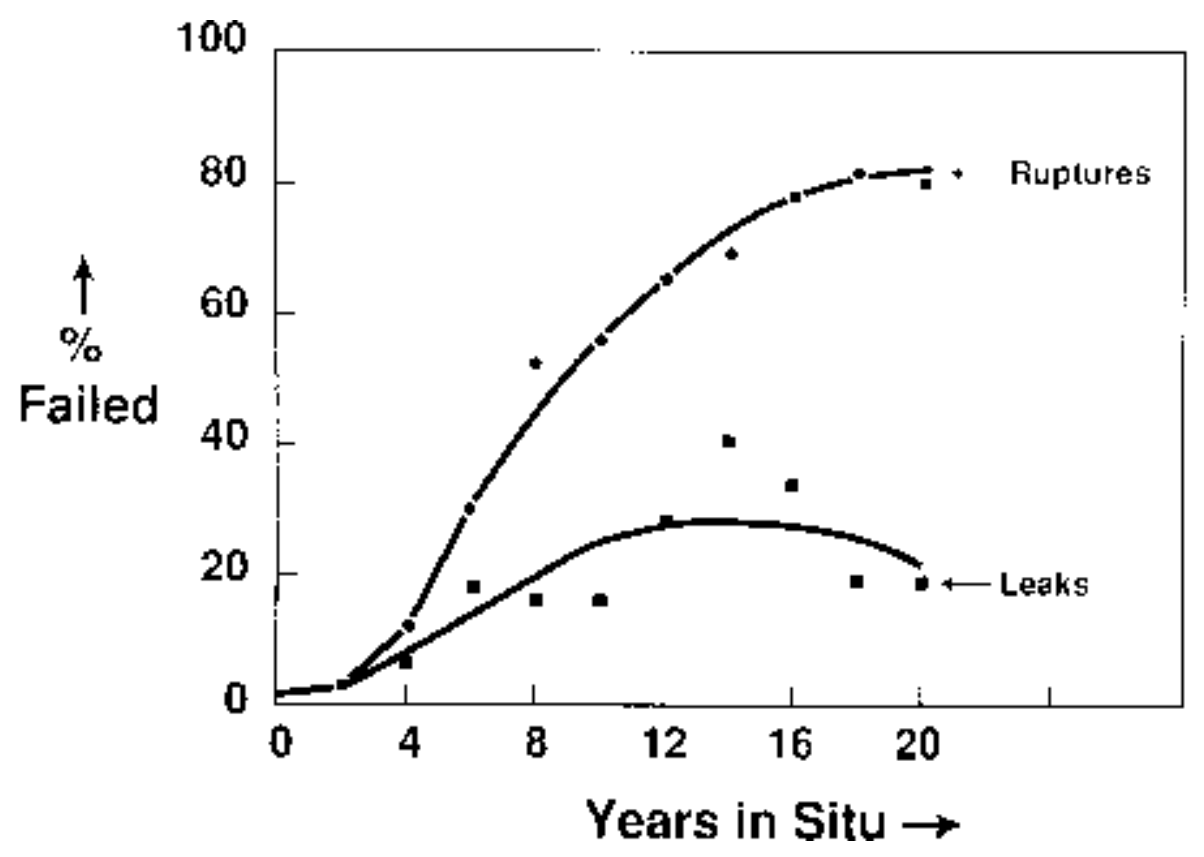

Figure 1) Implant integrity of 302 second generation silicone gel implants removed from 1981 to 1995 


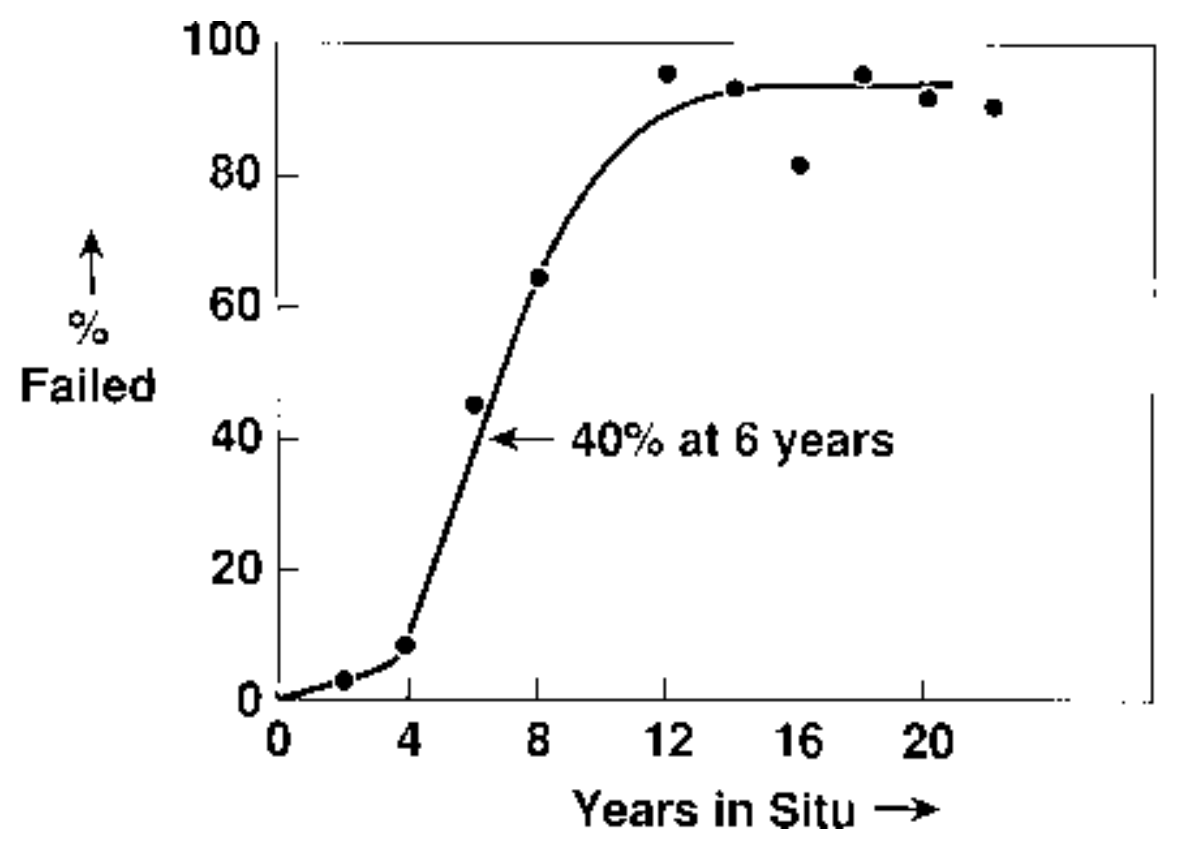

Figure 2) Implant integrity of 302 second generation silicone-gel implants removed from 1981 to 1995 (leaks and ruptures from Figure 1 are combined)

\section{DISCUSSION}

Mechanical failure of silicone-gel breast implants has proven to be more common than was previously appreciated. Through 1992, the rate of implant disruption was thought to be low -- in the range of 4 to $6 \%(7,8)$. In 1993, de Camara and co-workers analyzed 51 implants inserted from about 1973 onwards (9). Fifty-three percent were ruptured and $14 \%$ were leaking. All implants older than 10 years were leaking or ruptured. In 1994, Peters and colleagues (1) analyzed 102 implants and demonstrated a similar relationship between duration of implantation and implant failure. Only $7 \%$ of 45 implants which had been in place for five years or less showed failure. Of 29 implants in place for six to 10 years, $69 \%$ had failed. In 1995, Robinson and colleagues showed a similar failure rate of $63.5 \%$ in a large group of implants (6). The majority of these implants were second generation.

The present study indicates that $77 \%$ of patients with second generation siliconegel breast implants currently have leaking or ruptured implants. This failure begins after four years, involves $40 \%$ of implants after six years, and involves about $95 \%$ of implants after 12 years in situ. It should be pointed out that all of the patients in this study requested surgery because they were having problems related to their breast implants. In the first group of patients (1981 through 1991), 95\% demonstrated significant (Baker IIIIV) capsular contracture. In the second group, about $75 \%$ also had significant capsular contracture. A further $15 \%$ complained of other symptoms. It is possible, therefore, that 
the failure rate in the patients in this study may be higher than that of other populations of 'control' patients, who were not having problems related to their implants (11).

The etiology of implant failure remains to be fully elucidated. Implants may simply undergo a progressive deterioration with time. In addition, closed capsulotomy has been documented as a potential cause of implant failure $(12,13)$. Clinical studies, however, have not shown a direct correlation between disruption and closed capsulotomy $(6,13)$.

Of major concern today is the difficulty in diagnosing leaking or ruptured silicone-gel breast implants. Although mammography is helpful to diagnose extracapsular rupture $(6,14)$, only $5 \%$ of the patients in this study demonstrated extracapsular rupture. The vast majority of implant failures are intracapsular. The sensitivity rate of mammography to detect intracapsular rupture is only 11 to $16 \%(6,16)$. For patients with intracapsular rupture, magnetic resonance imaging (MRI) is helpful to predict rupture. However, its sensitivity rate is very operator dependent, and for most centres is probably in the range of about $50 \%(15,17)$. Ultrasound techniques and clinical evaluation are less accurate than MRI to predict rupture (5,16-18).

Based on the present study and other recent publications $(1,6,9)$, about $80 \%$ of all second generation silicone-gel implants are currently ruptured or leaking. Others are expected to rupture with further time. Should all second generation implants ultimately be explanted? The Food and Drug Administration has recommended that broken implants be removed. The gel was originally intended to be contained within the elastomeric shell. If the shell has failed, intuitive reasoning would suggest that these implants should be removed. However, implant removal has a significant morbidity, particularly regarding subsequent breast deformity. In addition, these patients originally sought surgery because of their breast size and shape. They may be particularly concerned about a secondary deformity. Furthermore, if these patients choose to have their gel implants replaced with saline implants, there may be significant cosmetic concerns about the visible 'rippling' associated with saline implants, particularly if they are inserted pre-pectorally.

Because of these reasons, most surgeons are currently hesitant to remove gel implants routinely from this large number of patients when there is not proof that they are ruptured. In addition, there have been no proven health concerns in patients, even with implant rupture. If patients have a significant degree of capsular contracture (Baker IIIIV), or other significant concerns, the decision to proceed with explantation may be easier, both for the patient and the surgeon.

If an implant has failed, should the capsule be removed during explantation? The capsular tissue contains a large foreign-body load of silicone (5). Capsulectomy seems reasonable in order to reduce this load, even though few deleterious effects have been demonstrated from leaving the capsule in place. Because the capsules of intact implants have been shown to contain silicon levels comparable to those of ruptured implants, one could also argue that consideration be given to the removal of all capsules at explantation. Currently, however, there is no uniform agreement about the role of routine capsulectomy when silicone-gel implants are removed.

ACKNOWLEDGEMENTS: This research was funded by a Medical Research Council of Canada University Industry grant, and by funding from Dow Corning Corporation 


\section{REFERENCES}

1. Peters WJ. Factors affecting the rupture of silicone-gel breast implants. Ann Plast Surg 1994;32:449-51.

2. Gruber RP, Friedman G. The pressures generated by closed capsulotomies of augmented breasts. Plast Reconstr Surg 1978;62:379-80.

3. Barker DE, Retsky MI, Schultz S. 'Bleeding' of silicone from bag-gel breast implants and its clinical relation to fibrous capsule reaction. Plast Reconstr Surg 1978;61:836-41. 4. Callahan T. Tensile strength and liquid silicone bleed. In FDA General Plastic Surgery Devices Panel Meeting, February 1992. Transcript Vol 1:73-84.

5. Peters WJ, Smith DC, Lugowski S, et al. An analysis of silicon levels in capsules of gel and saline breast implants and of penile prostheses. Ann Plast Surg 1995;34:578-84. 6. Robinson OG, Bradley EL, Wilsori DS. Analysis of explanted silicone implants: A report of 300 patients. Ann Plast Surg 1995;34:1-7.

7. Angell M. Breast implants: Protection or paternalism? N Engl J Med 1992;326:1695-6.

8. American Society of Plastic and Reconstructive Surgeons. Breast Implant Update, March 10, 1992.

9. de Camara DL, Sheridan JM, Kammer BA. Rupture and aging of silicone gel breast implants. Plast Reconstr Surg 1993;91:828-34.

10. Fisher JC. Invited discussion. Ann Plast Surg 1995;34:6-7.

11. Nelson GD. Complications from the treatment of fibrous capsular contracture of the breast. Plast Reconstr Surg 1980;66:969-70.

12. Eisenberg HV, Barrels JJ. Rupture of silicone bag gel breast implant by closed compressive capsulotomy. Plast Reconstr Surg 1979;59:849.

13. Peters WJ. The rupture of silicone-gel breast implants. Ann Plast Surg 1994;33:462-3. 14. Anderson B, Hawtof D, Alani H, et al. The diagnosis of ruptured breast implants. Plast Reconstr Surg 1989;84:903-7.

15. Ahn C, Shaw W, Narayaan K, et al. Definitive diagnosis of breast implant rupture using magnetic resonance imaging. Plast Reconstr Surg 1993;92:681-91.

16. Bassen LVW, Brenner RJ. Consideration when imaging women with breast implants. AJR 1992;159:979-81.

17. Peters WJ, Smith DC, Grosman H, Fornasier V. Role of mammography to assess complications of silicone gel breast implants. Can J Plast Surg 1995;3:150-6.

18. Peters WJ, Pugash R. Ultrasound analysis of 150 patients with silicone gel breast implants. Ann Plast Surg 1993;31:7-9. 